\title{
Adult Idiopathic Hypertrophic Pyloric Stenosis
}

\author{
Mena Boules, MD, Ricard Corcelles, MD, PhD, Esam Batayyah, MD, \\ John Rodriguez, MD, Matthew Kroh, MD \\ Department of General Surgery, Cleveland Clinic Main Campus, Cleveland, Ohio (all authors).
}

\begin{abstract}
Introduction: Adult idiopathic hypertrophic pyloric stenosis (AIHPS) is a rare entity. The most common clinical symptom is abdominal distention relieved by vomiting. There are several treatment modalities for relief of the pyloric obstruction.

Case Description/Technique: A 43-year-old woman presented with a long history of epigastric pain, nausea, vomiting, and bloating, which appeared to be caused by functional dyspepsia. She also reported severe postprandial epigastric pain that was thought to be secondary to peptic ulcer disease (PUD). She had lost $7 \mathrm{~kg}$, leading to a poor nutritional status. Further investigation by upper gastrointestinal endoscopy demonstrated moderate stenosis at the pylorus. After discussion, she elected to undergo laparoscopic Heineke-Mikulicz pyloroplasty. The patient was placed supine, and entrance into the peritoneal cavity was obtained with a $5-\mathrm{mm}$ optical trocar. The pylorus was clearly identified and was visibly thickened. Two 2-0 silk stay sutures were placed. Gastrotomy was made with a harmonic scalpel, and the pylorus was cut. The pylorus was reconstructed horizontally by using the Heineke-Mikulicz technique. Finally, a second layer of interrupted 2-0 silk sutures was placed.

Discussion: The etiology of AIHPS remains unclear. In a case report, Zarineh et al. classified AIHPS into two main types: primary and secondary. Several factors are important in establishing the diagnosis. The approaches include endoscopic dilation, gastrojejunostomy, partial gastrectomy, and pyloromyotomy with or without pyloroplasty. Despite the technical difficulty, operative procedures such as the Heineke-Mikulicz pyloroplasty have shown favorable results. Currently, laparoscopic pyloroplasty may represent a reasonable, less invasive option for this rare condition.
\end{abstract}

Key Words: Heineke-Mikulicz pyloroplasty, Hypertrophic pyloric stenosis, Pyloric obstruction.

Citation Boules M, Corcelles R, Batayyah E, Rodriguez J, Kroh M. Adult idiopathic hypertrophic pyloric stenosis. CRSLS e2014.00252. DOI: 10.4293/JSLS.2014.00252.

Copyright (c) 2015 by SLS, Society of Laparoendoscopic Surgeons. This is an open-access article distributed under the terms of the Creative Commons Attribution-Noncommercial-ShareAlike 3.0 Unported license, which permits unrestricted noncommercial use, distribution, and reproduction in any medium, provided the original author and source are credited.

This study was presented as a video at the Minimally Invasive Surgery Week/SLS Annual Meeting and Endo Expo, Las Vegas, Nevada, September 10-13, 2014

Address correspondence to: Mena Boules, MD, 9500 Euclid Avenue, A100, Cleveland, OH 44195, USA. Telephone: 360-621-3552, Fax: 216-444-2153, E-mail: boulesm@ccf.org

\section{INTRODUCTION}

Adult idiopathic hypertrophic pyloric stenosis (AIHPS) is a rare entity of uncertain pathogenesis. ${ }^{1}$ The literature reports that congenital pyloric stenosis is estimated to have an incidence of $0.2 \%$ to $0.5 \%$ of all live births. ${ }^{1-4}$ Jean Cruveilhier is thought to be the first to describe AIHPS (in 1835). ${ }^{5}$ The most common clinical symptom is abdominal distention relieved by vomiting. In addition, most patients with AIHPS experience weight loss. ${ }^{6}$ An upper gastrointestinal (GI) barium series and upper endoscopy are used to confirm the diagnosis and to rule out possible malignant disease. $5,7,8$ The treatment modalities for relief of pyloric obstruction include endoscopic dilation, pyloro- myotomy, pyloroplasty, gastrojejunostomy, and gastrectomy. ${ }^{9}$

\section{CASE REPORT}

A 43-year-old woman presented with a long-standing history of epigastric pain, nausea, vomiting, and bloating, caused by what appeared to be functional dyspepsia. The patient's medical history was not significant for gastroesophageal reflux disease (GERD) or peptic ulcer disease (PUD) and she had not undergone prior surgical interventions. The patient's medical treatment extended over more than 10 years, with the use of therapies such as sucralfate and antisecretory medications, which recently had failed 


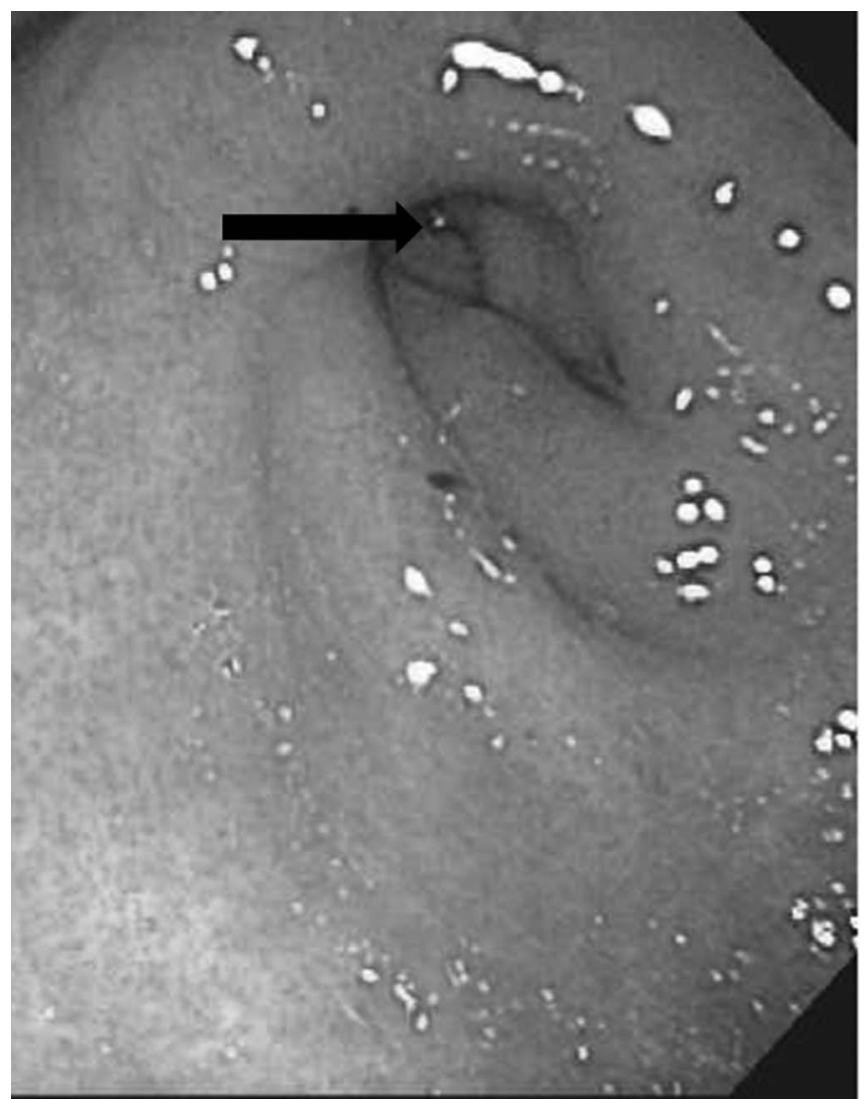

Figure 1. Esophagogastroduodenoscopy showed a benign-appearing, narrowed pyloric channel (arrow).

to control her symptoms. In addition, use of nonsteroidal anti-inflammatory agents, alcohol, or tobacco was ruled out. Upon her clinical encounter she also reported severe postprandial epigastric pain that was thought to be secondary to PUD. The patient's body weight was noted to be $55 \mathrm{~kg}$, with a body mass index of $19.6 \mathrm{~kg} / \mathrm{m}^{2}$. She reported that she had lost $7 \mathrm{~kg}$ within the past several months, leading to a suboptimal nutritional status. Her symptoms prompted further investigation through an upper gastrointestinal (GI) endoscopy, which demonstrated a benign-appearing, intrinsic, moderate stenosis at the pylorus (Figure 1). Biopsies revealed no evidence of malignant disease. Dilation was performed during the upper GI endoscopy with a 15-mm pyloric balloon, providing temporary relief of symptoms. An upper GI series confirmed these results, as did delayed emptying on a both the solid and liquid phases of a gastric emptying study. After a thorough discussion about the risks and benefits of the different treatment modalities the patient elected to undergo laparoscopic Heineke-Mikulicz pyloroplasty, which is considered to be a more durable

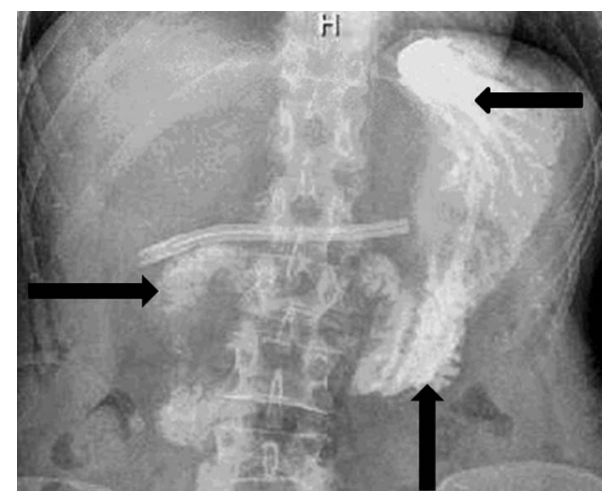

Figure 2. Upper GI series. The contrast opacifies the stomach and passes from the gastric body and antrum through the pylorus to the proximal duodenum without evidence of narrowing stricture or leak.

and definitive procedure than repeated endoscopic management.

The patient was placed supine, and entrance into the peritoneal cavity was obtained in the left lower quadrant with a 5-mm optical trocar. Initial diagnostic laparoscopy did not reveal any gross abnormalities. A 5-mm trocar was placed in the left upper quadrant and 5- and 12-mm trocars in the right lower quadrant, in addition to a Nathanson retractor, which was placed over the porta hepatis. A generous Kocher maneuver was performed. The pylorus was clearly identified and was visibly thickened in appearance. Two 2-0 silk stay sutures were placed and exteriorized, with a Carter-Thomason suture passer used for retraction. A gastrotomy was fashioned with ultrasonic shears, on the distal stomach $2 \mathrm{~cm}$ proximal to the pylorus. The longitudinal incision was then taken down onto the duodenum. The pylorus was reconstructed transversely with interrupted 2-0 braided, absorbable sutures, by using the Heineke-Mikulicz technique. Finally, a second layer of interrupted 2-0 silk sutures was placed. Upper endoscopy was performed, and the suture line was submerged in saline. There were no signs of leak or endoluminal bleeding, and the pylorus was easily traversable with the scope. A drain was placed anterior to the pyloroplasty, and the trocars were closed with 0 braided, absorbable sutures.

The patient's postoperative course was uneventful, and she was discharged home on postoperative day 2 on a liquid diet. A follow-up upper GI series exhibited normal passage without narrowing or stricture (Figure 2). At the 2-month follow-up, her symptoms had resolved. 


\section{DISCUSSION}

The etiology of AIHPS remains unclear, despite several theories advanced in the literature. In a case report $\mathrm{Za}-$ rineh et al. ${ }^{1}$ stratified the etiological classification of adult idiopathic hypertrophic pyloric stenosis to two main types: primary, which has no underlying pathology, and secondary, which may encompass several causes, including healing of a previous gastric or duodenal ulcer, cancer, postoperative adhesions, and vagus nerve hyperactivity, ultimately leading to hypertrophy of the muscular anatomy. $13,7,9,10$ In another report, Danikas and colleagues ${ }^{5}$ stratified AIHPS to three types. Type 1 was described as a late-stage, infantile, hypertrophic pyloric stenosis. Typically the patient has symptoms and a history that can be traced back to infancy. Type 2, the most common type, has an onset in adult life and is secondary to an underlying pathologic condition in the GI tract, such as duodenal and gastric ulcers, cancer, and other inflammatory diseases. Finally, idiopathic pyloric stenosis, which has an onset in adulthood without a known cause, was classified as type 3 . In this type, there is no history of vomiting during infancy. 5,6

Several factors are important in establishing the diagnosis: a thorough history and clinical examination of the patient, radiological findings, and visual confirmation through endoscopy, during which carcinoma and PUD must be excluded. The most common pathognomonic symptom is postprandial abdominal distention, with relief upon vomiting. In addition, most patients experience weight loss. 5,6 Some patients with AIHPS may have normal radiographic images. However, there are several radiographic findings in patients with AIHPS that may aid in establishing a diagnosis. Kirklin's sign, which is described as a convex indentation at the base of the duodenal bulb, is a strong indicator of AIHPS. Other findings include the string sign, which can be visualized as an eccentric or concentric narrowing of the pylorus. The radiographic findings may aid caregivers in differentiating between AIHPS and other possible diagnoses..$^{5-7,11}$

In the instances where radiographic findings are normal, an endoscopy is needed to establish diagnosis of AIHPS. In the literature, Schuster and Smith ${ }^{12}$ described an endoscopic finding in AIHPS of a narrow pylorus called the cervix sign. They reported that the cervix sign persists after anticholinergic therapy and can be differentiated from pylorospasm as pressure is applied through the endoscopy.1,12 A primary advantage in the use of endoscopy is the ability to differentiate AIHPS from other possible conditions. In addition, a histologic confirmation of the disease is recommended to rule out cancer.'

Both surgical and endoscopic therapies are intended to improve the symptoms secondary to outflow obstruction. There are several approaches, including endoscopic dilation, gastrojejunostomy, partial gastrectomy, and pyloromyotomy with or without pyloroplasty. Studies conducted by two groups indicated that endoscopic dilation may serve for temporary relief of symptoms, but it has a high rate of recurrence. Thus endoscopic therapy is typically reserved for candidates who present with a high surgical risk. ${ }^{5,13,14}$ Loop gastrojejunostomy alone allows for bypass of the affected area but does not directly address the disease process and is also associated with complications unique to the operation, such as afferent limb syndrome, and bile reflux gastritis. ${ }^{15-18}$ Pyloromyotomy has been effective in children with hypertrophic pyloric stenosis, but may also predispose patients to unwanted sequelae, such as mucosal laceration, pyloric scarring, and formation of diverticula. ${ }^{15}$ A less commonly used procedure, partial gastrectomy (with Billroth I or II anastomoses), has also been described. ${ }^{15}$ In the clinical scenario of a thickened pylorus, pyloroplasty is regarded as a challenging procedure. Despite the technical difficulty, operative procedures such as the Heineke-Mikulicz pyloroplasty have shown favorable results, owing to decreased operative time and good outcomes, which have been reported in the literature. Danikas et al. ${ }^{1}$ advocated laparoscopic pyloroplasty, due to the safety and effectiveness of the approach, in addition to the prompt recovery time, and reduced hospital stay. Currently, laparoscopic pyloroplasty may represent a reasonable, less invasive option for this rare condition.

\section{CONCLUSION}

AIHPS is a rare clinical condition that may mimic other more common GI syndromes. Minimally invasive surgery may be a viable option for the management of this condition.

\section{References:}

1. Zarineh A, Leon ME, Saad RS, Silverman JF. Idiopathic hypertrophic pyloric stenosis in an adult, a potential mimic of gastric carcinoma. Patholog Res Int. 2010;2010:614280.

2. Papaziogas B, Lazaridis C, Souparis A, et al. Idiopathic hypertrophic pyloric stenosis combined with left paraduodenal hernia in an adult. Med Princ Pract. 2007;16:151-154.

3. MacDonald JA. Adult hypertrophic pyloric stenosis. BrJ Surg 1973;60:73-75. 
4. Batcup G, Spitz L. A histopathological study of gastric mucosal biopsies in infantile hypertrophic pyloric stenosis. J Clin Pathol. 1979;32:625-628.

5. Danikas D, Geis WP, Ginalis EM, Gorcey SA, Stratoulias C. Laparoscopic pyloroplasty in idiopathic hypertrophic pyloric stenosis in an adult. JSLS 2000;4:173-175.

6. Du Plessis DJ. Primary hypertrophic pyloric stenosis in the adult. Br J Surg. 1966;53:485-492.

7. Dye TE, Vidals VG, Lockhart CE, Snider WR. Adult hypertrophic pyloric stenosis. Am Surg. 1979;45:478-484.

8. Levine SM, Brodmerkel G, Burke EL. Idiopathic adult hypertrophic pyloric stenosis: non-operative diagnosis and management. Gastrointest Endosc. 1969;16:26-29.

9. Simson JN, Thomas AJ, Stoker TA. Adult hypertrophic pyloric stenosis and gastric carcinoma. Br J Surg. 1986;73:379-380.

10. Ger R. Post-operative extrinsic pyloric stenosis. $\mathrm{Br}$ Med J. 1964;2:294.

11. Go TS, Morse WH. Hypertrophic pyloric stenosis in adults. Am J Gastroenterol. 1973;60:400-405.
12. Schuster MM, Smith VM. The pyloric "cervix sign" in adult hypertrophic pyloric stenosis. Gastrointest Endosc. 1970;16:210211.

13. Lau JY, Chung SC, Sung JJ, et al. Through-the-scope balloon dilation for pyloric stenosis: long-term results. Gastrointest Endosc. 1996;43:98-101.

14. Kuwada SK, Alexander GL. Long-term outcome of endoscopic dilation of nonmalignant pyloric stenosis. Gastrointest Endosc. 1995;41:15-7.

15. Hellan M, Lee T, Lerner T. Diagnosis and therapy of primary hypertrophic pyloric stenosis in adults: case report and review of literature. J Gastrointest Surg. 2006;10:265-269.

16. Quigley RL, Pruitt SK, Pappas TN, Akwari O. Primary hypertrophic pyloric stenosis in the adult. Arch Surg. 1990;125:12191221.

17. North JP, Johnson JH. Pyloric hypertrophy in the adult. Ann Surg. 1950;131:316-329.

18. Craver WL. Hypertrophic pyloric stenosis in adults. Gastroenterology. 1957;33:914-924. 